\title{
Investigation of Shear Response of Fibrous Reinforced Concrete Beams Using Incremental-Iterative Method
}

\author{
S. A. Al-Ta'an \\ N. S. Al-Saffar
}

Civil Engineering Department, Mosul University

\begin{abstract}
The brittle nature of concrete leads to a brittle shear failure, which the designers try always to avoid by making the flexural strength of the member less than the shear strength. The addition of steel fibers to concrete converts the brittle characteristics of concrete to a ductile one, such fibers are uniformly distributed and randomly oriented throughout the volume of the concrete. The steel fibers are suitable as shear reinforcement especially in thin members such as slabs and thin webs, where the use of shear reinforcement is not possible.

An incremental- iterative method which utilizes the equations of equilibrium, compatibility of deformations and materials constitutive relationships is employed to find out the complete response of beams under increasing shear loads. The method gives detailed information about the flexural and shear stresses in concrete, steel stresses, cracks initiation and propagation and failure loads. The results obtained such as failure load and failure pattern showed good agreement with some published experimental results.
\end{abstract}

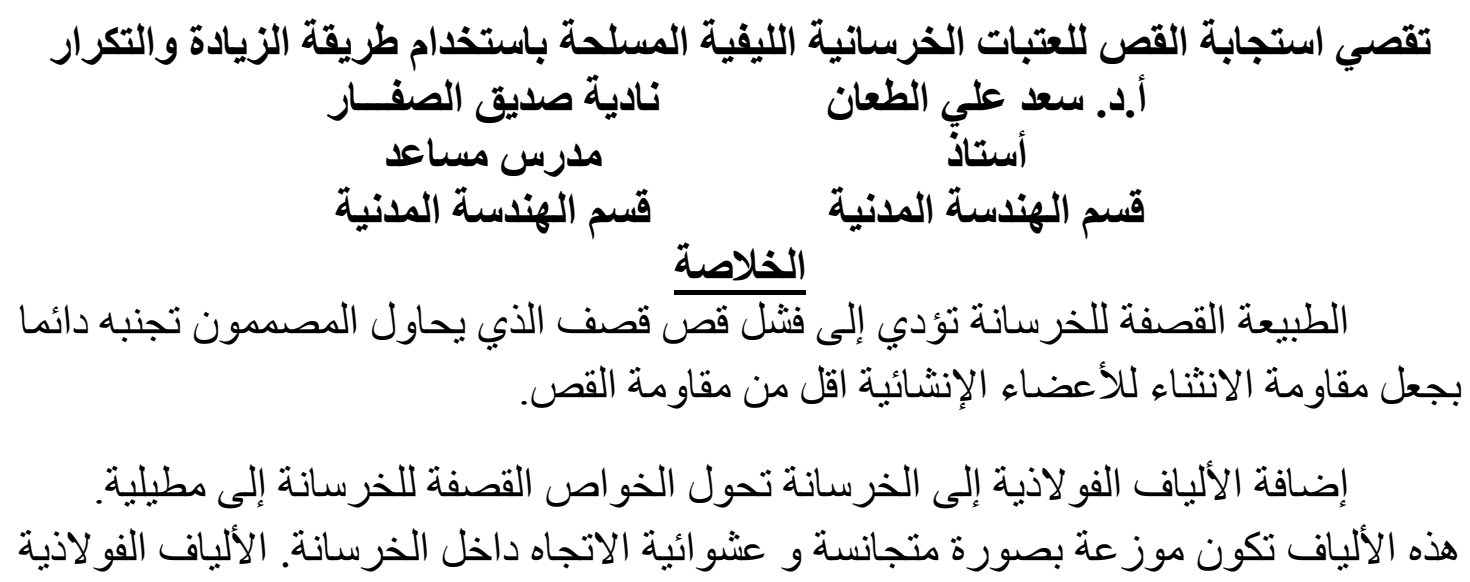


ملائمـة كتسليح قص خاصـة في الأعضـاء ذات السمك القليل مثل البلاطـات و الوترات القليلة السمك حيث لا يمكن استعمال تسليح القص الاعتيادي.

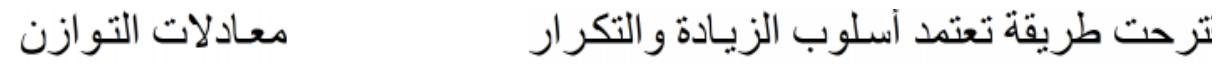

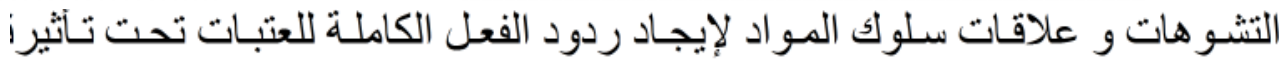

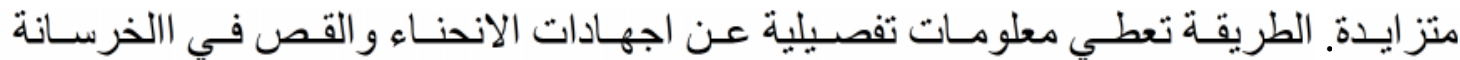

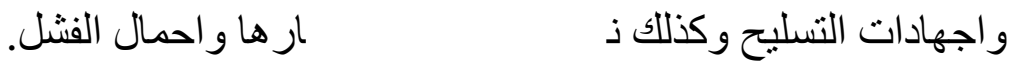

ت ت توا فقاً جيداً مع النتائج العملية المنشورة

Keywords: Concrete, fibers, incremental method, iteration, reinforced concrete, response, shear.

InReoduedißn: May 2006

Accepted 27 Sep. 2006

Various studies have been carried out to enhance the weak properties of concrete and cement mortar. In certain cases, short pieces of steel fibers are used as reinforcement for cementatious materials to prevent brittle fracture and improve some of the weak mechanical properties. The composite exhibits improved post-cracking tensile behavior which would increase the shear strength of reinforced concrete members significantly.

The greatest difficulty in solving the problem of shear behavior of SFRC (Steel Fiber Reinforced Concrete) beams is the large number of parameters involved, such as, shear span to depth ratio, concrete strength, reinforcement ratio, fibers content, fibers type and fibers aspect ratio.

To predict some properties of fibrous concrete or the behavior of steel fibrous reinforced concrete members, empirical and semi- empirical equations were proposed which may give a good approximation with respect to experimental results. Concerning the shear strength of steel fibrous reinforced concrete shallow beams, various methods have been proposed (1-5) to predict the cracking and shear strength. These methods take into account the influencing parameters, such as the concrete strength, reinforcement ratio, shear span to depth ratio and the fibers properties. These methods predict the shear strength at the onset of cracking and at ultimate stage. Strains and stresses in steel and concrete and cracks initiation and propagation cannot be traced by these methods. 
Tan et al. [6] presented an investigation on the behavior of steel fibrous reinforced concrete beams subjected to increasing shear loads. The cross-section of the beam is divided into a suitable number of concrete and steel layers. For a given loading, the shear stress in each concrete layer is estimated assuming constant shear flow across the beam section. A trial value of the top and bottom longitudinal fiber strains $\varepsilon_{x}$ are assumed and the longitudinal strain for each layer is then computed. A trial value of the principal compressive strain $\varepsilon_{d}$ for a given layer and the inclination of the principal plane $\alpha$ is assumed and the strains in each layer is calculated using the following relations:

$\varepsilon_{x}=\varepsilon_{d} \cos ^{2} \alpha+\varepsilon_{r} \sin ^{2} \alpha$

$\varepsilon_{y}=\varepsilon_{d} \sin ^{2} \alpha+\varepsilon_{r} \cos ^{2} \alpha$

$\gamma_{x y}=2\left(\varepsilon_{d}-\varepsilon_{r}\right) \sin \alpha \cdot \cos \alpha$

where, $\varepsilon_{x}$ and $\varepsilon_{y}$ are the average strains in the $\mathrm{x}$ and $\mathrm{y}$-directions respectively (tension is positive),

$\gamma_{x y}=$ average shear strain,

$\varepsilon_{d}$ and $\varepsilon_{r}$ are the average principal (compressive and tensile) strains, respectively. From the above principal strains the stresses $\sigma_{d}$ and $\sigma_{r}$ are computed using the following stress-strain relationships [6]:

$$
\sigma_{d}=f_{c}^{\prime}\left[2\left(\frac{\varepsilon_{d}}{\varepsilon_{o}}\right)-\lambda \cdot\left(\frac{\varepsilon_{d}}{\varepsilon_{o}}\right)^{2}\right] \text { for }\left|\varepsilon_{d}\right| \leq\left|\varepsilon_{p}\right|
$$


$\sigma_{d}=\frac{f_{c}^{\prime}}{\lambda}\left[1-\left(\frac{\frac{\varepsilon_{d}}{\varepsilon_{o}}-\frac{1}{\lambda}}{2-\lambda}\right)^{2}\right]$

for

$\left|\varepsilon_{d}\right|>\left|\varepsilon_{p}\right|$

where $\varepsilon_{p}=\varepsilon_{o} / \lambda, \varepsilon_{O}$ is the strain at peak stress $f_{c}$ and $\lambda$ is a softening coefficient to account for the softening phenomenon and is taken as :

$\lambda=\sqrt{0.7-\frac{\varepsilon_{r}}{\varepsilon_{d}}}$

in which $\varepsilon_{r}$ is the strain corresponding to the principal tensile stress $\sigma_{r}$, which was calculated as follow:

$\sigma_{r}=\varepsilon_{r} E_{c} \quad$ for $\varepsilon_{r} \leq \varepsilon_{c r}$

$\varepsilon_{c r}$ is the cracking strain:

$\varepsilon_{c r}=f_{c r} / E_{c}$

$f_{c r}$ and $E_{c}$ are the cracking stress and elastic modulus respectively: 
$f_{c r}=0.33 \sqrt{f_{c}}$

$E_{c}=2 f_{c}^{\prime} / \varepsilon_{o}$

The post-cracking stress was calculated by using the following formula which was proposed by Lim et al. [7]:

$\sigma_{r}=\frac{f_{c r}+\left(\beta^{\prime} . \sigma_{t u}\right)}{1+\beta^{\prime}} \quad$ for $\varepsilon_{r}>\varepsilon_{c r}$ (11)

where $\beta^{\prime}=\sqrt{\frac{\varepsilon_{r}-\varepsilon_{c r}}{0.005}}$

The stresses in the $\mathrm{x}$ and $\mathrm{y}$-directions are then calculated as follow:

$\sigma_{x}=\sigma_{d} \cos ^{2} \alpha+\sigma_{r} \sin ^{2} \alpha+\rho_{x} . f x$

$\sigma_{y}=\sigma_{d} \sin ^{2} \alpha+\sigma_{r} \cos ^{2} \alpha+\rho_{y} f y$

where $\rho_{x}$ and $\rho_{y}$ are the reinforcement ratio in the $\mathrm{x}$ and $\mathrm{y}$-directions respectively, and $f_{x}$ and $f_{y}$ are the steel stresses in the $\mathrm{x}$ and $\mathrm{y}$-directions respectively. The angle $\alpha$ is recalculated from these stresses and new principal strains and stresses are calculated again and this process is repeated until the values of the strains, stresses and the angle $\alpha$ converge to an acceptable degree of accuracy. The shear stress $\tau_{x y}$ is then calculated for each layer and element and the above steps are repeated 
until the values of $\tau_{x y}$ converges. After the strain and stress values converge, the section equilibrium is checked by summing the stresses as follow:

$M=\sum_{i=1}^{n} \sigma_{x}^{i} \cdot a^{i} \cdot y^{i}$

$F=\sum_{i=1}^{n} \sigma_{x}^{i} \cdot a^{i}$

$V=\sum_{i=1}^{n} \tau_{x y}^{i} a^{i}$

where M, F, V are the applied external moment, axial force, and shear force, respectively, and $a^{i}$, is the area of layer $\mathrm{i}$ and $\mathrm{n}$ is the number of the layer. These steps are repeated for different values of the load to obtain the complete response of the beam.

In this investigation a method of predicting the shear response is proposed which is based on the equilibrium of forces, compatibility of deformations, geometrical and material properties of the member. This method gives a complete shear response with a detailed stress and strain history in the beams. The method differs from that proposed by Tan et al. [6]. The proposed method starts with the stresses and strains induced at the cracking stage and updated in the subsequent loading stages depending on the load level and convergence is attained in fewer iterations.

\section{Materials Constitutive Relationships:}


The principal compressive stress $\sigma_{d}$ is calculated by using the stressstrain relationship proposed by Ezeldin and Balaguru [8] for fibrous concrete:

$$
\frac{f_{c}}{f_{c}^{\prime}}=\frac{\beta^{\prime \prime}\left(\varepsilon / \varepsilon_{p o}\right)}{\beta^{\prime \prime}-1+\left(\varepsilon / \varepsilon_{p o}\right)^{\beta^{\prime \prime}}}
$$

where

$f_{c}^{\prime}=$ cylinder compressive strength of concrete.

$\varepsilon_{p o}=$ strain corresponding to the peak compressive stress $f_{c}$.

$f_{c}, \varepsilon=$ stress and strain values on the curve.

$\beta^{\prime \prime}=$ is a material parameter that can be calculated by using the following equations:

$\beta^{\prime \prime}=1.093+0.7132 R I^{-0.926} \quad$ for hooked fibers

$\beta^{\prime \prime}=1.093+7.4818 R I^{-1.387} \quad$ for smooth fibers

Nataraja et al.[9] proposed the same equation for crimped fibers, but with the following value of $\beta^{\prime \prime}$ :

$\beta^{\prime \prime}=0.5811+1.93 R I^{(-0.7406)}$

R.I. = reinforcing index of the steel fibers related to the weight fraction of the fibers and is equal to $w_{f} . l_{f} / d_{f}$.

An equation proposed in Ref. [10] to calculate the ultimate strain $\varepsilon_{c u}$ in compression is adopted in this study and it is as follows:

$\varepsilon_{c u}=3011+2295 V_{f} \quad$ (microstrains)

......(20)

The tensile strength of steel fibrous concrete is enhanced more than the compressive strength and the equation proposed by Soroushian and Lee [11] is used in this investigation:

$$
\mathrm{f}_{\mathrm{tf}}=\mathrm{f}_{\mathrm{t}}^{\prime}\left(1+0.016 \mathrm{~N}_{\mathrm{f}}^{1 / 3}+0.05 \pi \cdot \mathrm{d}_{\mathrm{f}} \cdot \mathrm{l}_{\mathrm{f}} \cdot \mathrm{N}_{\mathrm{f}}\right)
$$


Where $f_{t}^{\prime}=$ tensile strength of matrix or concrete (MPa)

$N_{f}=$ number of fibers per unit area and is equal to:

$N_{f}=\beta V_{f} /\left(\pi \cdot d_{f}^{2}\right)$

$\beta=$ orientation factor $\left(\beta=0.41\right.$ according to Ref.[12]) and $V_{f}$ is the volume fraction of fibers in concrete.

An equation for the strain at peak stress in tension is also proposed in Ref. [11] for fibrous concrete and used in this investigation:

$$
\varepsilon_{t f}=\varepsilon_{t}\left(1+0.35 N_{f} d_{f} l_{f}\right)
$$

Where $\varepsilon_{t}=$ matrix cracking strain $=f_{t}^{\prime} / E_{c}$

A bilinear constitutive model was suggested in Ref. [11] as shown in Fig. (1) to represent the tensile stress-strain curve of steel fibrous concrete prior to the peak tensile stress as follows:

Path OA, elastic uncracked portion:

$\sigma=E_{c} . \varepsilon$

Path $\mathrm{AB}$, initiation of micro-cracks,

$$
\sigma=E_{c r}\left(\varepsilon-\varepsilon_{t}\right)+f_{t}^{\prime}
$$

where;

$$
E_{c r}=\frac{f_{t f}-f_{t}^{\prime}}{\varepsilon_{t f}-\varepsilon_{t}}
$$

The post -peak tensile behavior of SFRC is controlled by pullout action of fibers. Fig.(1) represents the path CD of the stress strain relationship, which is derived on the basis of fracture energy by Visalvanich and Naaman et al. [13] and adopted in Ref.[10] and is given in the following form:

$$
\sigma=f_{u}\left[\frac{\varepsilon_{i}-\varepsilon_{m}}{\varepsilon_{t f}-\varepsilon_{m}}\right]^{2}
$$


where, $\mathrm{f}_{\mathrm{u}}$ is the post - cracking tensile strength and is given as:

$$
f_{u}=N f \cdot \tau_{u} \cdot \pi \cdot d_{f} \cdot \frac{l_{f}}{4}
$$

$f_{u}=0.41 V_{f} \cdot \tau_{u} \frac{l_{f}}{d_{f}}$

where $\tau_{u}$ is the bond strength of steel fibers

An empirical expression of bond strength of steel fibers was determined by Soroushian and Lee [11] and used in Ref.[10] and in this study also.

$$
\tau_{u}=(2.62-0.0036 N f)
$$

In order to include the effect of fiber shape a so-called (shape factor) $k_{f}>1.0$ [14-16] is incorporated into Eq. (30), then

$\tau_{u}=(2.62-0.0036 N f) k_{f}$

$\varepsilon_{i}=$ The tensile strain at the point considered

$\varepsilon_{m}=$ The limiting tensile strain; Fig.(1).

$\varepsilon_{m}=\frac{3 G_{f}}{h \cdot f_{u}}+\varepsilon_{t f}$

$G_{f}=$ Fracture energy as derived in Ref. [13], and is equal to:

$G_{f}=0.04592 \frac{V_{f} \cdot l_{f}^{2}}{d_{f}}$

$\mathrm{h}=$ average crack spacing [17]. In the present study the previous model of stress-strain relationship of SFRC is replaced by a continuous function as proposed in Ref. [18] and is given by:

$\sigma=\frac{a^{\prime} \cdot \varepsilon}{\varepsilon^{3}+b^{\prime} \cdot \varepsilon^{2}+c^{\prime} \cdot \varepsilon+d^{\prime}}$

where

$a^{\prime}, b^{\prime}, c^{\prime}$ and $d^{\prime}$ are constants and $\varepsilon$ is the strain which corresponds to stress $\sigma$. 
The constants are determined by using four points on the stress-strain curve and these are represented by the points A, B, C and any point that lies at the curve $\mathrm{CD}$ in Fig. (1). By solving four equations the constants $a^{\prime}, b^{\prime}, c^{\prime}$, and $d^{\prime}$ can be determined. Fig. (2) shows a typical tensile stressstrain relationships using the last modification for different percents of fiber volume fraction.

For concrete in biaxial tension-compression, the formula proposed in Ref. [19] which takes into account the softening effect of tension on the compression is used in this study:

$$
f_{C 2 M A X}=\frac{f_{c}^{\prime}}{0.8-0.34\left(\frac{\varepsilon_{r}}{\varepsilon_{p o}}\right)} \leq 1.0
$$

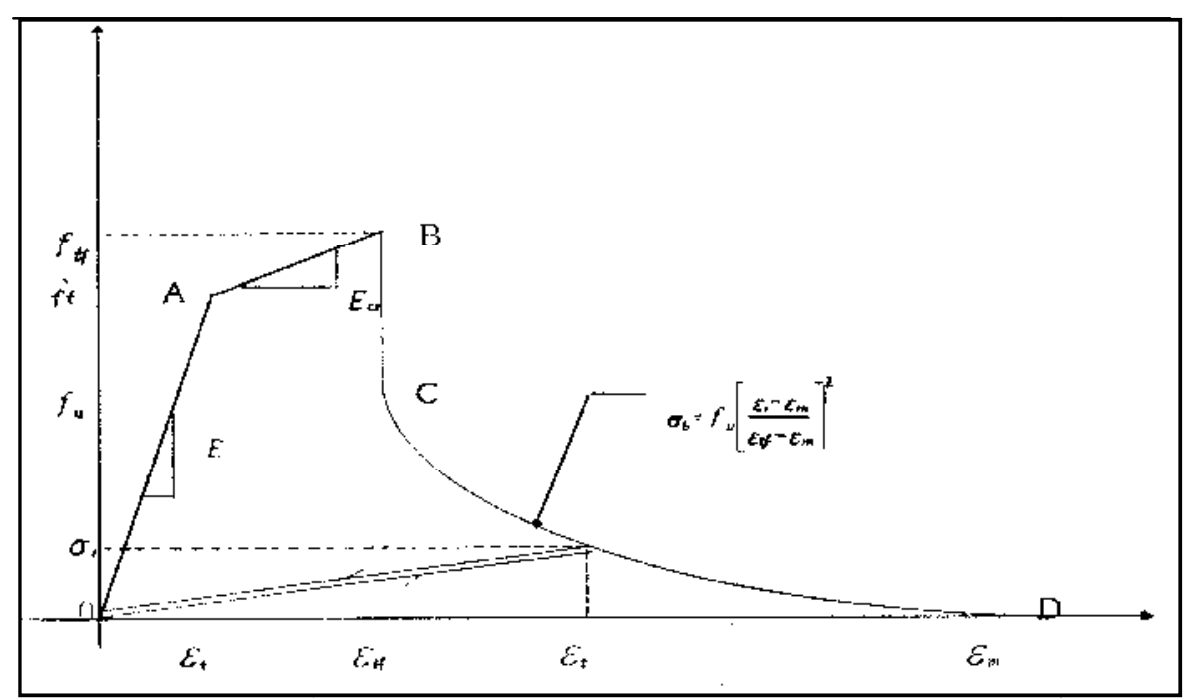

Fig. (1) Analytical Model of SFRC in Tension [9] 


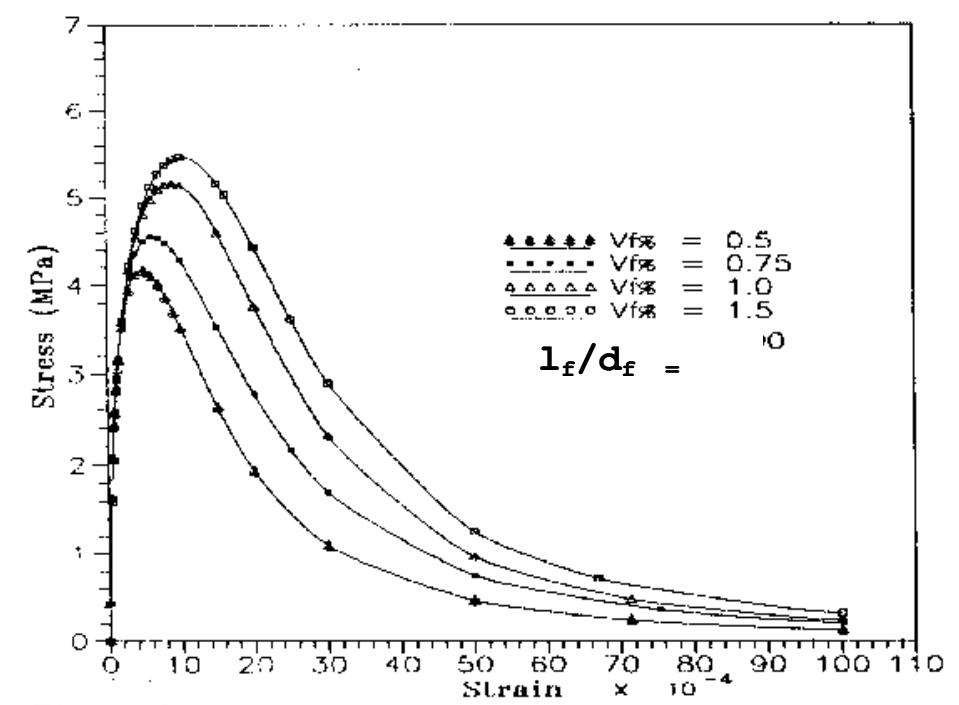

Fig. (2) Tensile Stress-Strain Relationship

\section{The Proposed Incremental-Iterative Method:}

In this method the equations of equilibrium, compatibility of deformations and the material constitutive relationships are used to trace the behavior of reinforced concrete fibrous beams under predominate shear. The method can be summarized as follows:

(1) The shear span is divided into a number of sections and the depth into a finite number of layers.

(2) The cracking moment and the corresponding shear force is calculated first. The corresponding strain and stress distribution are found assuming:

(a) Plane sections before bending remain plane after bending.

(b) Normal stress distribution is linear in this stage.

(c) The shear stress distribution is calculated by using the following equation: 


$$
\tau_{x y}=\frac{V \cdot Q}{I . b}
$$

where

$\mathrm{V}=$ applied shear force at the section considered,

$\mathrm{Q}=$ first moment of the area confined between the point considered and the nearest face.

$\mathrm{I}=$ second moment of area and

$b=$ width of section where the shear stress is calculated.

(d) The shear strain is calculated assuming elastic relationship between shear strains and stresses:

$$
\gamma_{x y}=\frac{\tau_{x y}}{G}
$$

where, $G$ is the modulus of rigidity.

(3)The strains are then modified to satisfy the compatibility relationships of Eqs.(1-3)

(4) The principal stresses $\sigma_{d}$ and $\sigma_{r}$ are then calculated using the proposed materials constitutive relationships.

(5) The normal stresses $\sigma_{x}$ and $\sigma_{y}$ are then integrated at each section to calculate the internal moment $M_{i}$ at each section.

$$
M_{i}=\sum_{j=1}^{n} \sigma_{x j} \cdot y_{j} \cdot b \cdot \Delta h
$$

where,

$\sigma_{x j}=$ concrete stress at the center of the layer $\mathrm{j}$.

$b=$ width of the section at the point considered

$\Delta h=$ layer thickness 
$y_{j}=$ distance from the center of the layer to the neutral axis.

$\mathrm{n}=$ number of layers.

(6) The external moment at each section is compared with the internal moment; if they differ by more than $3 \%$, the neutral axis and the strain distribution are updated (modified) to satisfy again the equilibrium and compatibility conditions for flexure.

(7)The shear stresses $\tau_{x y}$ are also integrated to calculate the internal shear force:

$V_{\mathrm{int}}=\sum_{j=1}^{n} \tau_{x y j} . b . \Delta h$

(8) If the internal shear $V_{\text {int }}$ differs by more than $3 \%$ of the external shear $V_{\text {ext }}$; the shear stresses and strains are modified accordingly. The strains and stresses are recalculated and steps (3- 8) are repeated until convergence is achieved at all sections.

(9) Another load increment is applied and the stresses and strains are updated as follow:

$\varepsilon_{k}=\varepsilon_{k-1} \cdot \frac{M_{k}}{M_{k-1}}$

where

$\sigma_{k} / \varepsilon_{k}=$ is the current stress/strain of the $k t h$ load increment;

$\sigma_{k-1} / \varepsilon_{k-1}=$ stress /strain of the previous load increment.

$M_{k}=$ external moment of the $k t h$ load increment at a certain section.

$M_{k-1}=$ external moment of the previous load increment at a certain section. 
(10) The shear stresses and strains are updated as follows:

$$
\tau_{x y(k)}=\tau_{x y(k-1)} \cdot \frac{V_{k}}{V_{k-1}}
$$

$$
\gamma_{x y(k)}=\gamma_{x y(k-1)} \cdot \frac{V_{k}}{V_{(k-1)}}
$$

where

$\tau_{x y(k)} / \gamma_{x y(k)}=$ shear stress / strain of the ${ }^{\varepsilon}$ po load increment;

$\tau_{x y(k-1)} / \gamma_{x y(k-1)}=$ shear stress/ strain of the previous load increment;

$V_{k}=$ external shear of the $k t h$ load increment.

$V_{(k-1)}=$ external shear of the previous load increment.

\section{Discussion of results:}

The proposed method was applied to fifteen fibrous reinforced concrete beams tested previously $[2,3,5]$ and whose details are shown in Table (1). The average value of the Calculated to the experimental shear strength was 0.968 with a coefficient of variation of $9.4 \%$.

Table (1) Details of Beams and Results Obtained by using the Proposed Incremental- Iterative Method

\begin{tabular}{|c|l|l|l|l|l|l|l|l|l|l|l|l||}
\hline Bea & Re & $\mathrm{b}$ & $\mathrm{D}$ & $\mathrm{h}$ & $\mathrm{a} / \mathrm{d}$ & $\mathrm{V}_{\mathrm{f}}$ & $f_{c}^{\prime}$ & $\mathrm{A}_{\mathrm{s}}{ }^{\prime}$ & $\mathrm{A}_{\mathrm{s}}$ & $\mathrm{Ex}$ & $\mathrm{Cal}$. & Cal. \\
$\mathrm{m}$ & $\mathrm{f}$. & & & & & $\%$ & $\mathrm{MP}$ & $m m^{2}$ & $m m^{2}$ & $\mathrm{p}$. & $\mathrm{vu}$ & Exp. \\
No. & & & & & & & $\mathrm{a}$ & & & $\mathrm{MP}$ & \\
& & & & & & & & & & $\mathrm{M}$ & & \\
\hline
\end{tabular}




\begin{tabular}{|c|c|c|c|c|c|c|c|c|c|c|c|c|}
\hline & & & & & & & & & & $\overline{\mathrm{Pa}}$ & $\overline{\mathrm{a}}$ & \\
\hline $\bar{~} 1$ & 3 & $\begin{array}{c}15 \\
0\end{array}$ & $\begin{array}{c}19 \\
7\end{array}$ & $\begin{array}{c}22 \\
5\end{array}$ & 2.0 & .75 & 29.9 & $\overline{0}$ & 396 & $\begin{array}{c}2.8 \\
8\end{array}$ & 3.03 & $\begin{array}{r}1.05 \\
3\end{array}$ \\
\hline 2 & 2 & 75 & $\begin{array}{c}13 \\
7\end{array}$ & $\begin{array}{c}15 \\
0\end{array}$ & 2.5 & .75 & 31.4 & 79 & 158 & $\begin{array}{c}2.1 \\
5\end{array}$ & 2.2 & $\begin{array}{r}1.02 \\
4\end{array}$ \\
\hline 3 & 3 & $\begin{array}{c}15 \\
0\end{array}$ & $\begin{array}{c}19 \\
7\end{array}$ & $\begin{array}{c}22 \\
5\end{array}$ & 2.8 & .75 & 33.4 & 0 & 591 & $\begin{array}{c}2.9 \\
1\end{array}$ & 2.05 & $\begin{array}{r}0.70 \\
4\end{array}$ \\
\hline 4 & 3 & $\begin{array}{c}15 \\
0\end{array}$ & $\begin{array}{c}19 \\
7\end{array}$ & $\begin{array}{c}22 \\
5\end{array}$ & 2.8 & .75 & 29.9 & 0 & 591 & 2.2 & $\begin{array}{c}2.04 \\
7\end{array}$ & $\begin{array}{r}0.93 \\
0\end{array}$ \\
\hline 5 & 3 & $\begin{array}{c}15 \\
0\end{array}$ & $\begin{array}{c}19 \\
7\end{array}$ & $\begin{array}{c}22 \\
5\end{array}$ & 2.8 & .75 & 29.9 & 0 & 384 & $\begin{array}{c}2.0 \\
3\end{array}$ & $\begin{array}{c}2.03 \\
1\end{array}$ & $\begin{array}{r}1.01 \\
0\end{array}$ \\
\hline 6 & 3 & $\begin{array}{c}15 \\
0\end{array}$ & $\begin{array}{c}19 \\
7\end{array}$ & $\begin{array}{c}22 \\
5\end{array}$ & 3.6 & .5 & 29.1 & 0 & 396 & $\begin{array}{c}1.5 \\
2\end{array}$ & 1.42 & $\begin{array}{r}0.93 \\
5\end{array}$ \\
\hline 7 & 3 & $\begin{array}{c}15 \\
0\end{array}$ & $\begin{array}{c}19 \\
7\end{array}$ & $\begin{array}{c}22 \\
5\end{array}$ & 2.8 & .5 & 29.1 & 0 & 396 & \begin{tabular}{|c|}
1.7 \\
8
\end{tabular} & $\begin{array}{c}1.73 \\
6\end{array}$ & $\begin{array}{r}0.97 \\
6\end{array}$ \\
\hline 8 & 3 & $\begin{array}{c}15 \\
0\end{array}$ & $\begin{array}{c}19 \\
7\end{array}$ & $\begin{array}{c}22 \\
5\end{array}$ & 2.0 & .5 & 29.1 & 0 & 396 & $\begin{array}{c}2.5 \\
4\end{array}$ & \begin{tabular}{|c}
2.54 \\
4
\end{tabular} & $\begin{array}{r}1.00 \\
2\end{array}$ \\
\hline 9 & 2 & 75 & $\begin{array}{c}13 \\
7\end{array}$ & $\begin{array}{c}15 \\
0\end{array}$ & 2.5 & .75 & 30.6 & 79 & 158 & \begin{tabular}{|c|}
2.3 \\
7
\end{tabular} & 2.15 & $\begin{array}{r}0.90 \\
7\end{array}$ \\
\hline 10 & 2 & 75 & $\begin{array}{c}13 \\
7\end{array}$ & $\begin{array}{c}15 \\
0\end{array}$ & 2.5 & \begin{tabular}{|l}
.75 \\
\end{tabular} & 29.2 & 79 & 158 & $\begin{array}{c}2.7 \\
2\end{array}$ & 2.66 & $\begin{array}{r}0.97 \\
7\end{array}$ \\
\hline 11 & 2 & 75 & $\begin{array}{c}13 \\
7\end{array}$ & $\begin{array}{c}15 \\
0\end{array}$ & 2.5 & .75 & 31.2 & 79 & 158 & 2.7 & 2.89 & $\begin{array}{r}1.07 \\
0\end{array}$ \\
\hline 12 & 5 & $\begin{array}{c}10 \\
0\end{array}$ & $\begin{array}{c}18 \\
2\end{array}$ & $\begin{array}{c}20 \\
0\end{array}$ & 1.5 & .75 & 53 & 0 & 400 & $\begin{array}{c}5.4 \\
4\end{array}$ & \begin{tabular}{|l|}
5.49 \\
\end{tabular} & $\begin{array}{r}1.00 \\
9\end{array}$ \\
\hline 13 & 5 & $\begin{array}{c}10 \\
0\end{array}$ & $\begin{array}{c}18 \\
2\end{array}$ & $\begin{array}{c}20 \\
0\end{array}$ & 2.0 & .75 & 53 & 0 & 400 & $\begin{array}{c}3.5 \\
7\end{array}$ & $\begin{array}{c}3.65 \\
7\end{array}$ & $\begin{array}{r}1.02 \\
5\end{array}$ \\
\hline
\end{tabular}




\begin{tabular}{||r|r|c|c|c|c|c|c|c|c|c|c|r||}
\hline 14 & 5 & $\begin{array}{c}10 \\
0\end{array}$ & $\begin{array}{c}18 \\
2\end{array}$ & $\begin{array}{c}20 \\
0\end{array}$ & 2.5 & .75 & 53 & 0 & 400 & 3.4 & 2.97 & 0.87 \\
1 & & & & & & & & & \\
15 & 5 & 10 & 28 & 30 & 2.5 & .75 & 53 & 0 & 560 & 3.2 & 3.3 & 1.02 \\
& & 0 & 0 & 0 & & & & & & 2 & & 5 \\
\hline
\end{tabular}

Fig.(3-a) shows the steel stress variation along the shear arm for three load levels. The figure shows the logical increase in the steel stress with increasing load, the figure also shows cracks initiation at the zone of high bending moment followed by propagation upwards and then initiation of the inclined shear cracks.

Figs. (4, and 5) show the longitudinal concrete stress contours at three load levels and the stress distribution at two sections also within shear span zone for beam No. (1). The figures show the increase of the stresses with increasing load. The neutral axis remains nearly at the same position and the concrete stresses are approximately linear unlike the flexural failure where the neutral axis rises with increasing load and the concrete stresses reach their ultimate values.

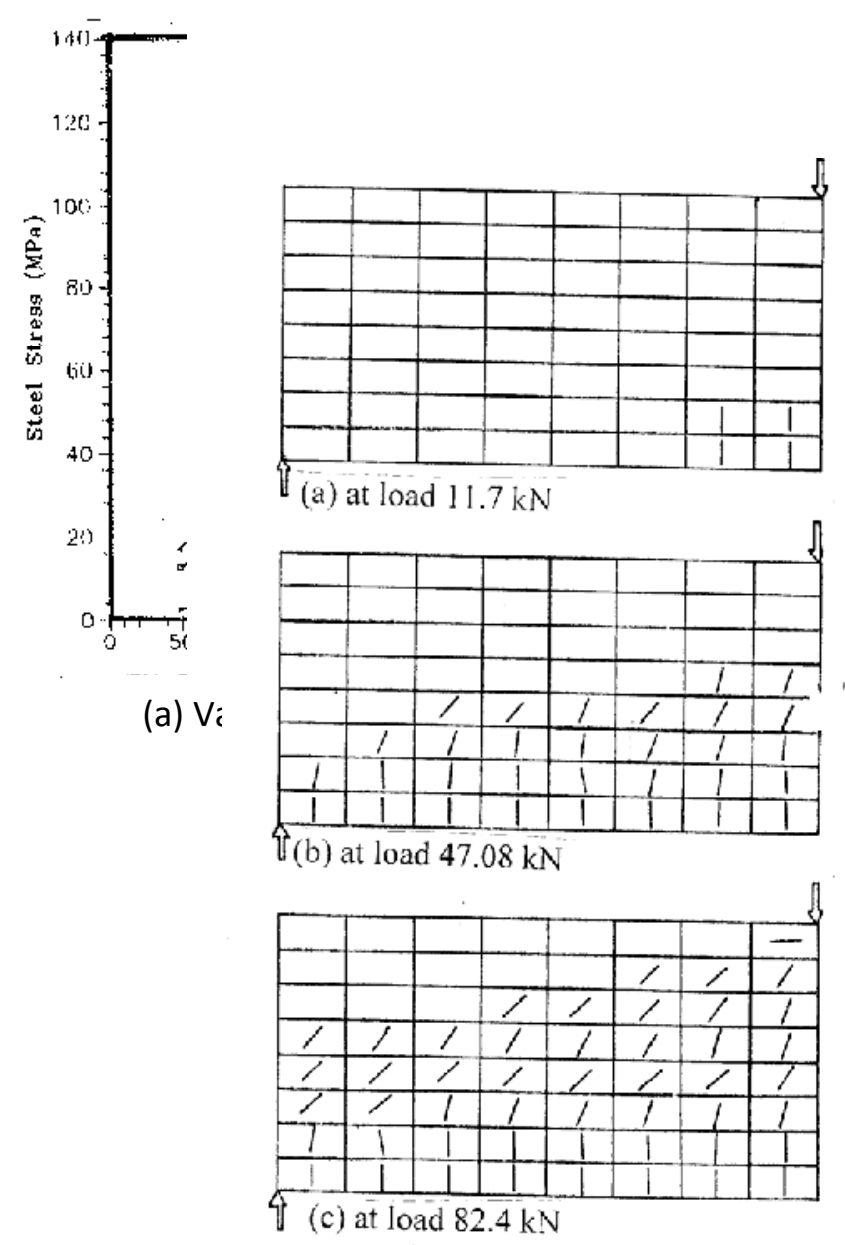


(b) Crack Pattern variation with load.

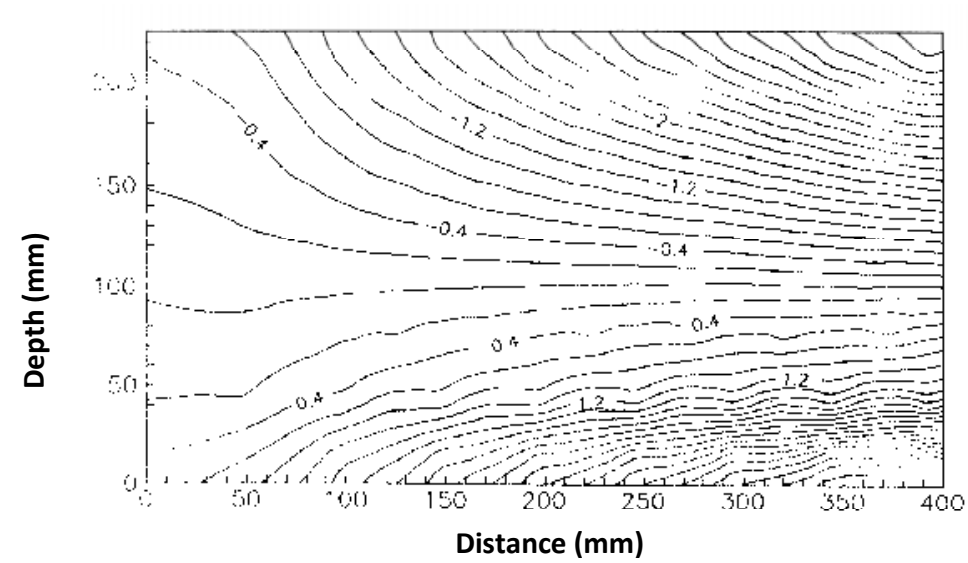

eam No.(1)

(a) Longitudinal Stress at Load 11.77 kN

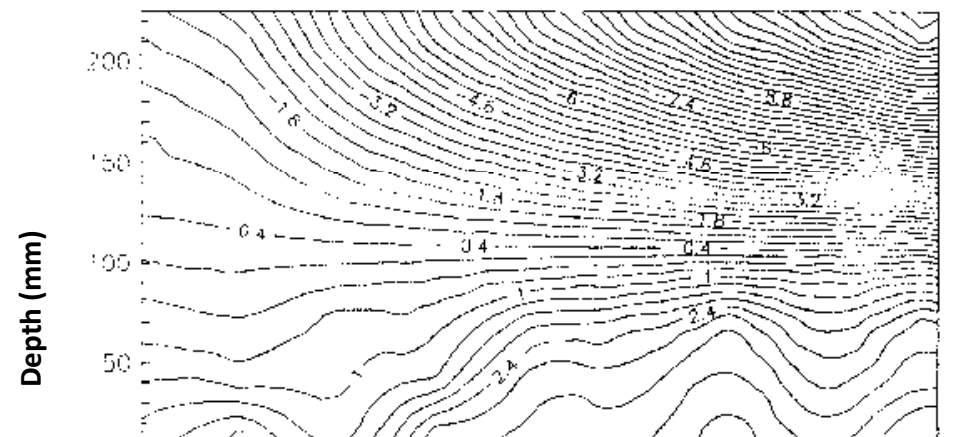



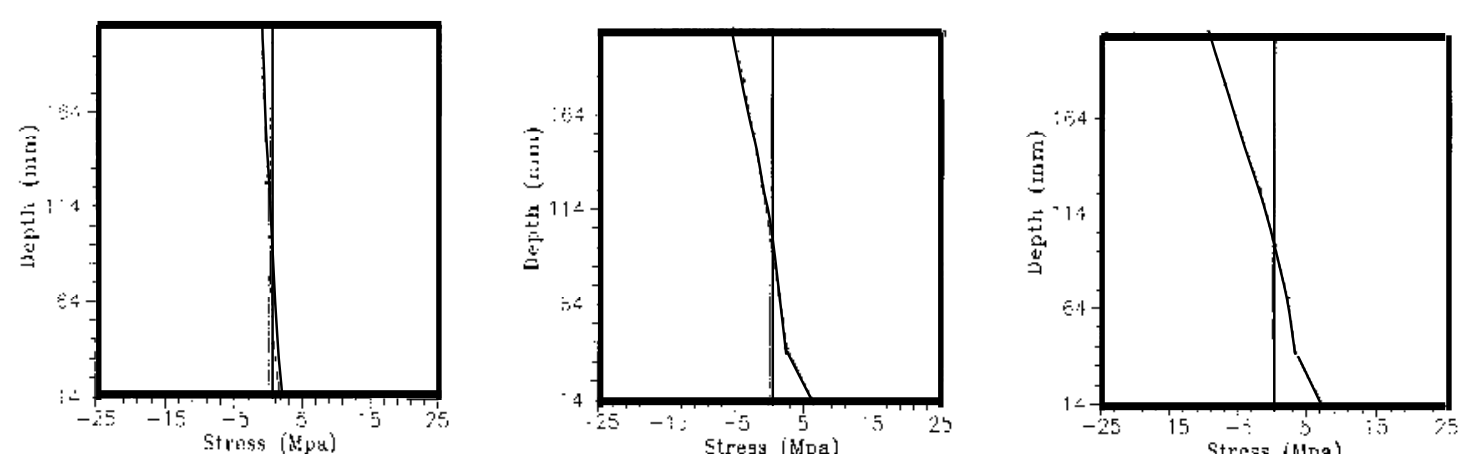
Figs. (6, and 7) show the shear stress contours at three load levels and the shear stress distribution at two sections of beam No. (1). The figures show the increase of the shear stresses with increasing load and give the approximately parabolic distribution of the shear stresses. 


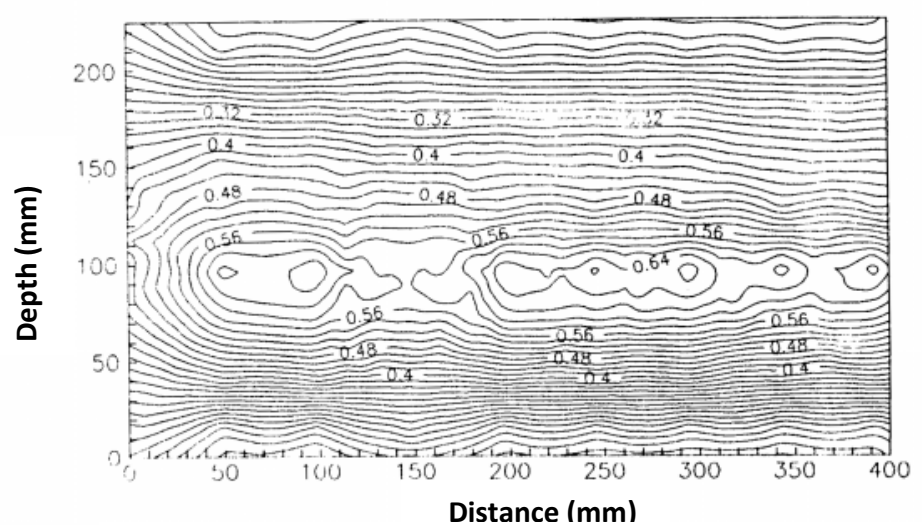

(a) Longitudinal Stress at Load 11.77 kN

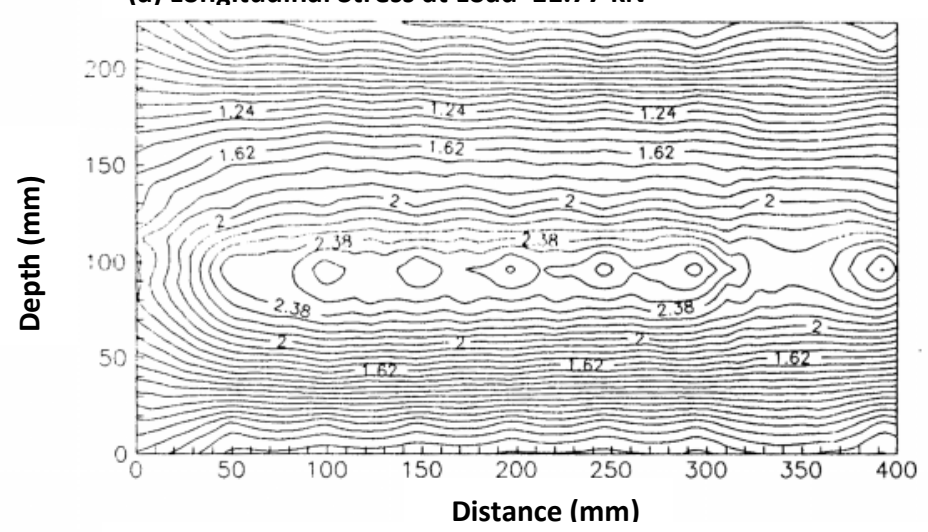

(b) Longitudinal Stress at Load $47.08 \mathrm{kN}$

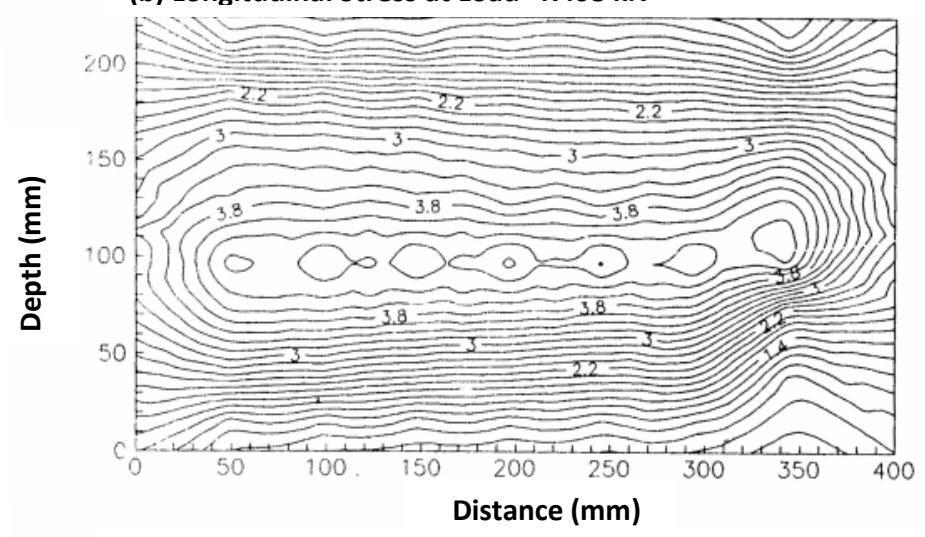

(c) Longitudinal Stress at Load $82.08 \mathrm{kN}$

Fig. (6) Shear Stress Contours at Loads 11.77, 47.08, 82.4 (kN), for Beam No. (1). 


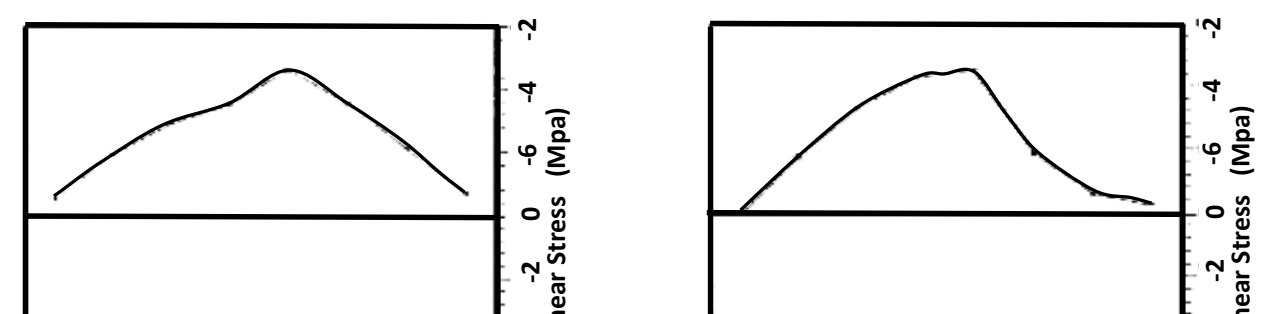



Fig. (7) Shear Stress at Loads 11.77, 47.08, $82.4(\mathrm{kN})$

\section{Conclusions:}

The proposed incremental- iterative method with the adopted convergence criterion which employs the equations of equilibrium, compatibility of deformations and material constitutive relationships simulate the behavior of fibrous reinforced concrete beams with predominant shear and gives reliable stress distribution, crack propagation, failure load and failure pattern. The method may be extended to deep beams by taking into account the nonlinear strain distribution due to the noticeable shear deformation.

\section{References:}

1. Sharma, A.K., "Shear Strength of Steel Fiber Reinforced Concrete Beams", ACI Jour. Proceeding, Vol. 83, No. 4, July-August 1986 pp. 624-628. 
2. Kadir, M. R. A. and Saeed, J. A.," Shear Strength of Fiber Reinforced Concrete Beams", Journal of Engineering and Technology, IRAQ, Vol. 4 No.3 (1986), pp. 98-112.

3. Mansur, M. A., Ong, K.C.G., and Paramasivam, P., "Shear Strength of Fibrous Concrete Beams Without Stirrups", Proceedings of the American Society of Civil Engineers, Journal of the Structural Division Vol. 112, No. ST9, September 1986, pp. 2066-2079.

4. Narayanan, R., and Darwish, I.Y.S., "Use of Steel Fiber as Shear Reinforcement", ACI Structural Journal, V.84, No.3, May-June 1987, pp. 216-227.

5. Uomoto, T., Ranjan K., Weeraratne, Furukosh H., Fujino H. ," Shear Strength of Reinforced Concrete Beams with Fiber Reinforcement ", Proc. RILEM Symp. FRC 86. On Development in Fiber Reinforced Cement and Concrete, Volume 2, RILEM Technical Committee 49-TFR, July 1986, pp. 553-562.

6. Tan, K. H., Murugappan, K., and Paramasivam, P., "Shear Behavior of Steel Fiber Reinforced Concrete Beams", ACI Structural Journal, Vol. 90, No.1, January-February 1993, pp. 3-11.

7. Lim, T. Y, Paramasivam, P. and Lee, S. L," Bending Behavior of Steel Fiber Concrete Beams", ACI Structural Jour., Vol. 84, No. 6, Nov.-Dec. 1987, pp.524-536.

8. Ezeldin, A. S. and Balaguru, P. N. 1992. "Normal and High Strength Fiber Reinforced Concrete under Compression", Journal of Materials and Engineering, ASCE, Vol.4, No. 4, pp. 415-427.

9. Nataraja, M. C., Dhang, N. and Gupta, A. P. 1999. "StressStrain Curves for Steel-Fiber Reinforced Concrete under Compression", Cement and Concrete Composites, Vol. 21, pp.383-390.

10. Abdul-Razzak, A. A., "Nonlinear Finite Element Analysis of Reinforced Concrete Structural Members", Ph.D. Thesis, University of Mosul, IRAQ, August 1996, 237 pp.

11. Soroushian, P., and Lee, C.D., "Constitutive Modeling of Steel Fiber Reinforced Concrete Under Direct Tension and Compression”, Proc. The Inter. Conf. on Recent Developments in Fiber Reinforced Cements and Concrete, 18-20 Sept. 1989, Cardiff (U.K.), Swamy and Barr, Elsevier Applied Science, pp. 363-377. 
12. Romualdi, J. P., and Mandel, J. A., "Tensile Strength of Concrete Affected by Uniformly Distributed Closely Spaced Short Lengths of Wire Reinforcement”, ACI J., Vol. 61, No. 6, June 1964, pp. 657-671.

13. Visalvanich, K., and Naaman, A.E., "Fracture Model for Fiber Reinforced Concrete", ACI Journal, Proceedings, Vol. 80, No. 2, Mar.Apr. 1983, pp. 128-138.

14. Al-Ta' an, S. A., and Ali, T.Q.M, "Nonlinear Finite Element Analysis of Reinforced Fibrous Concrete Beams", Proceedings of the Sixth Arabian Conference on Structural Engineering, Damascus, Syria, 21-24 October 1995.

15. Al-Ta'an, S.A., and Ezzadeen, N.A., "Flexural Analysis of Reinforced Fibrous Concrete Members Using the Finite Element Method", J. of Computers and Structures, Vol. 56, No. 6, Sept. 1995, pp. 1065-1072.

16. Henager, C. H., " Ultimate Strength of Reinforced Steel Fibrous Concrete Beams", Proc. of the ICE Conference on Fiber Reinforced Cement and Concrete: Engineering Applications; ICE (London), March 1977, pp. 151-160.

17. Al-Saffar, N. S., "Prediction of Shear Strength of Steel Fiber Reinforced Concrete Members", M. Sc. Thesis, Mosul University, 1999, $102 \mathrm{pp}$.

18. Al-Sulayfani, B. J. "Contribution a l'tude du comporementdes ossatures enbeton arme sous sollicitations Cycliques par analysis nonlineaire globale. Docteur de i'Universite de Nantes, Spcialite genie Civil, 1986.

19. Vecchio, F. J. and Collins, N. P. "The Modified Compressive Field Theory for Reinforced Concrete Elements subjected to Shear ", ACI Jour., Vol. 83, No. 2, March- April 1986, pp. 219-231. 